\title{
THE VEGETATIVE PROPAGATION OF LEAF-BUNDLE CUTTINGS OF RED PINE Pinus resinosa ${ }^{1}$
}

\author{
BY HERBERTS J. JECKALEJS ${ }^{2}$
}

Herberts-Johans Jeckalejs, born August 27, 1912, in Riga, Latvia. Forestry Engineer, Forestry Faculty, Agricultural Academy of Jelgava, Latvia, 1941. Additional studies at the University of Uppsala, Sweden, 1950 to 1951. Employed as Forest Engineer and Logging Superintendent, Department of Forests, Riga, 1934 to 1940; District Forester, Slitere District, Latvia, 1941 to 1944. Escaped from occupied Latvia in 1944 and proceeded to Sweden; worked first as Assistant Forester in the Stromsrum Forests, in experimental plantings at the University of Lund, 1945 to 1946; and later on investigations of insect damage and control by aerial dusting of forests and in forest nurseries for the State Forest Research Institute, Stockholm, Sweden, 1947 to 1948; Supervisor of land use assessments, mapping, and forest management for industry in Sweden, 1949 to 1951; proceeded to Canada in 1951 and since engaged in research work related to forest nursery problems in Ontario.

\begin{abstract}
The subject of vegetative propagation of coniferous species of forest trees is reviewed, and preliminary results obtained in rooting of leaf-bundle cuttings of red pine are presented.

\section{FOREWORD}

This paper presents the preliminary results obtained in a joint research project supported by the Forest Biology Division, Department of Agriculture, Ottawa; the Division of Research, Ontario Department of Lands and Forests; and, at the outset, by the Ontario Research Council. In undertaking this project, attention was focused upon the conviction that, through vegetative propagation, difficulties encountered in other methods which permit the random assortment of inherited characteristics might be avoided. The evolution of a uniform and simple method of perpetuating the desirable features of trees of good form and quality, vegetatively, posed a number of major problems. Some of these have been successfully solved and significant progress has been made in our efforts to provide a standard practice for the propogation of selected trees. The attainment of this objective will be of value to all tree breeders, and especially to those concerned with the development of trees resistant to disease and insect attacks.-L. T. White, Officer-in-Charge, Forest Pathology Laboratory, Maple, Ontario.

'Contribution No. 239 from the Forest Biology Division, Science Service, Department of Agriculture, Ottawa, Canada.

${ }^{2}$ Forester, Ontario Department of Lands and Forests, Southern Research Station, Maple, Ont. Referred for direction in this co-operative project to the Forest Parhology Laboratory, Maple, Ont.
\end{abstract}




\section{INTRODUCTION}

In silviculture, work has been directed, continually, towards discovering more suitable methods for preserving the innate characteristics of high quality races of trees through succeeding generations. Usually this is attempted through one of two methods: the provision and use of good seed material or the use of vegetative propagation.

In a number of countries, careful registration of superior stands, or even of separate "elite" trees has been used to ensure a high quality of seed. Since, however, the control of pollination in these situations is not practical, there is always a possibility that a portion of the seeds so obtained will be of lower quality.

There are, too, other methods by which seeds of good quality may be obtained, as, for example, through the establishment of "tree orchards" where four- to eight-year-old trees are grafted with scions taken from outstanding specimens. In those cases, it is possible to control pollination completely and so preserve, at least in part, the innate characteristics of the grafted material in the seeds. It is possible also in tree orchards to use practices which will advance the time of flowering and cone setting.

Vegetative propagation of conifers, using cuttings, has been attempted. Although extensive investigations in this field have been undertaken by Mirov $(1,2,3)$ in the United States, the method has not been developed for practical application in silviculture.

A method which shows greater promise in the vegetative propagation of conifers involves the use of excised leaf-bundles. Some original experiments in this field were undertaken by Toda $(4,5)$ in Japan. Toda, after treating leafbundles of Pinus densiflora Sieb. \& Zucc. with alpha-napthalene-acetic acid, planted them, for the most part, in a Kanuma soil ${ }^{3}$. In due course, roots and buds developed. It is not indicated, however, that the procedure was developed to a stage which found an application in silvicultural practice.

The development of a method by which leaf-bundles might be used for propagation in large quantities without difficulty would be of great importance to foresters. Such a development would permit outstanding progress in a program of vegetative propagation, and in addition to its more obvious practical application in silviculture, would provide new opportunities for research upon the innate qualities of various coniferous species.

The following paragraphs outline some experimental results obtained in a study of root formation in leaf-bundles of red pine, Pinus resinosa Ait.

\section{EXPERIMENTAL RESUlTS}

In preparation for these experiments $2 / 0$ seedlings of red pine were transplanted from nursery beds to flower pots in autumn and retained in a greenhouse. In the spring, a group of 25 newly-developed leaf-bundles were separated from the stem and placed in $50 \mathrm{ml}$. beakers containing the hormone, methoxone (2-methyl, 4 chlorophenoxyacetic acid) in concentrations of $10^{-8} \mathrm{M}$ and $10^{-7} \mathrm{M}$. The basal portions of the leaf-bundles were immersed to a depth of $2 \mathrm{~mm}$. in the solutions and the treatment time for each concentration was 12 and 24 hours (Table 1).

: Kanuma soil $=$ a werthered pumice. 
MARCH, 1956

TABLE I

\begin{tabular}{rccc}
\hline Group & $\begin{array}{c}\text { Number of } \\
\text { Leaf-bundles } \\
\text { per group }\end{array}$ & $\begin{array}{c}\text { Methoxone } \\
\text { Concentration }\end{array}$ & $\begin{array}{c}\text { Time for } \\
\text { Treatment } \\
\text { (hours) }\end{array}$ \\
\hline $\mathbf{I}$ & 25 & $10^{-0} \mathrm{M}$ & $\mathbf{1 2}$ \\
$\mathbf{U}$ & 25 & $10^{-0} \mathrm{M}$ & $\mathbf{2 4}$ \\
III & 25 & $10^{-7} \mathrm{M}$ & $\mathbf{1 2}$ \\
IV & 25 & $10^{-7} \mathrm{M}$ & $\mathbf{2 4}$ \\
\hline
\end{tabular}

After immersion, the leaf-bundles were rinsed in distilled water and planted at a depth of $8 \mathrm{~mm}$. in wooden boxes $\left(12^{\prime \prime} \times 18^{\prime \prime} \times 8^{\prime \prime}\right)$ containing a mixture of coarse sand $(0.2-2.0 \mathrm{~mm}$.) and sterilized (frozen) peat moss combined in a ratio of $1: 1$. Boxes were covered with glass plates and the moisture content of the rooting medium was maintained by watering with warm water $\left(70^{\circ} \mathrm{F}\right)$. The temperature of the rooting medium varied from $75^{\circ}$ to $85^{\circ} \mathrm{F}$., although the air temperature in the greenhouse, on sunny days, reached $105^{\circ} \mathrm{F}$. Light intensity within the culture boxes was reduced by about 50 per cent with suitable screens.

The experiment was commenced on June 14. At the end of a two-month period the number of live and dead leaf-bundles and the occurrence of roots and calluses were recorded (Table 2 ).

TABLE 2

Number of Rooted Leaf-Bundles, Calluses Formed, Live and Dead

LEAF-BundLes AT END OF 2 MONTHS

\begin{tabular}{rcccccccc}
\hline Group & $\begin{array}{c}\text { Number } \\
\text { of Leaf- } \\
\text { bundles }\end{array}$ & $\begin{array}{c}\text { Meth- } \\
\text { oxone } \\
\text { Concen- } \\
\text { tration }\end{array}$ & $\begin{array}{c}\text { Time for } \\
\text { Treat- } \\
\text { ment } \\
\text { (hours) }\end{array}$ & $\begin{array}{c}\text { Rooted } \\
\text { Leaf- } \\
\text { bundles }\end{array}$ & $\begin{array}{c}\text { Calluses } \\
\text { formed }\end{array}$ & $\begin{array}{c}\text { Non- } \\
\text { rooted }\end{array}$ & Dead \\
\hline I & 25 & $10^{-0} \mathrm{M}$ & 12 & $\mathbf{8}$ & 7 & 4 & 6 \\
II & 25 & $10^{-0} \mathrm{M}$ & 24 & 12 & 5 & 3 & 5 \\
III & 25 & $10^{-7} \mathrm{M}$ & 12 & 10 & 4 & 9 & 2 \\
IV & 25 & $10^{-7} \mathrm{M}$ & 24 & 17 & 3 & 4 & $\mathbf{1}$ \\
\hline
\end{tabular}

It will be observed that greatest success was obtained in leaf-bundles which had been subjected to hormone treatment of $10^{-7} \mathrm{M}$ concentration for a 24 -hour period. In this group 17 to 25 leaf-bundles had developed roots. Less success was obtained in leaf-bundles subjected to other concentrations or treatment times.

In successful cases in all groups, the primary root was vigorous, 1 to 3 cms. long, and possessed secondary roots. Roots were light brown in color and possessed white tips. Needles exhibited a normal green color (Fig. 1). 

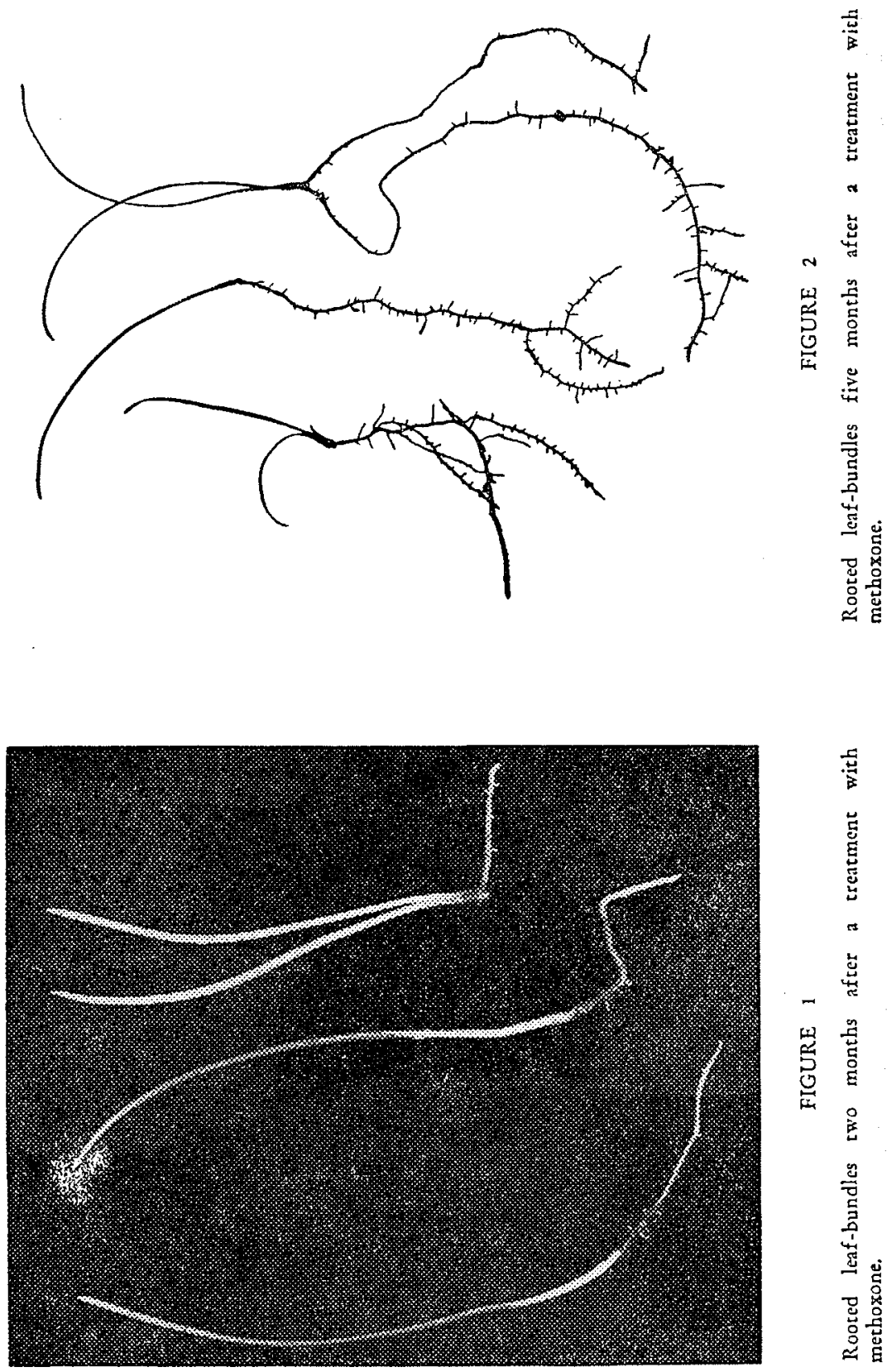

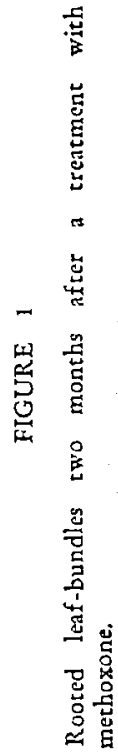


Rooted leaf-bundles were transplanted to flower pots for further observation. The same soil as before was used but a small quantity of mineral soil from a red pine stand was added at this stage. The potted seedlings were retained in the greenhouse at temperatures varying between $80^{\circ}$ and $110^{\circ} \mathrm{F}$. for one year. Periodic examinations showed that the root systems continued to enlarge with the production of additional long and short roots (Fig. 2).

In addition to experiments using fascicles from $2 / 0$ seedlings, similar experiments were undertaken using leaf-bundles from 7 -year-old red pine. In this case, also, roots were obtained.

It is evident that leaf-bundles of red pine can be induced to form root systems. There can be little doubt that with closer control of temperature, light, and moisture it will be possible to not only obtain certain rooting, but also provide the budding as reported in experiments with $P$. densiflora.

It should be noted, here, that recent refinements in techniques have satisfactorily solved the problem of ensuring bud formation. Excision of the distal portions of new shoots of red pine at the beginning of the growth period has resulted in leaf-bundles bearing well-defined buds. There can be no doubt that leaf-bundles with pre-developed buds will root without difficulty. With the successful completion of this procedure the problem of obtaining vegetative propagation of red pine using excised leaf-bundles may be considered virtually solved. Undoubtedly, other coniferous species, important to silviculture, may be propogated in a similar manner.

\section{REFERENCES}

1. MIROV, N. T., 1938. Vegetative propogation of white pine 25 a possible method of blister rust control. J. Forestry, 34:807-808.

2. MIROV, N. T., 1944. Experiments in rooting pines in California. J. Forestry, 42:199-204.

3. MIROV, N.T., 1941. Distribution of growth hormone in shoots of two species of pine. J. Forestry, 39:457-464.

4. TODA, R., 1948. Rooting responses of leaf-bundle cuttings of pine. Bull. Tokyo University Forests, 36:41-48.

5. TODA, R., 1948. The conversion of buds into roots in the leaf-bundle cuttings of pine. Bull,Tokyo University Forests, 36:49-53. 